\title{
State of Research in Adult Hospital Medicine: Results of a National Survey
}

\author{
Vineet Chopra, MD, MSc ${ }^{1 *}$; Marisha Burden, MD2; Christine D Jones, MD, MS²; Stephanie Mueller, MD, MPH; \\ Vineet Gupta, MD; Neera Ahuja, MD; Alana Sigmund, MD; Shaker M Eid, MD, MBA; \\ on behalf of the Society of Hospital Medicine Research Committee ${ }^{8}$.
}

\begin{abstract}
${ }^{1}$ The Division of Hospital Medicine, Department of Medicine, University of Michigan, Ann Arbor, Michigan; ${ }^{2}$ Division of Hospital Medicine, University of Colorado, Aurora, Colorado; ${ }^{3}$ Hospital Medicine Unit, Division of General Internal Medicine, Brigham and Women's Hospital, Boston, Massachusetts; ${ }^{4}$ Division of Hospital Medicine, University of California San Diego, San Diego, California; ${ }^{5}$ Section of Hospital Medicine, Stanford University School of Medicine, Palo Alto, California; ${ }^{6}$ Hospital for Special Surgery, New York, New York; ${ }^{7}$ Division of Hospital Medicine, Johns Hopkins Bayview Medical Center, Baltimore, Maryland; ${ }^{8}$ Society of Hospital Medicine, Philadelphia, Pennsylvania.
\end{abstract}

BACKGROUND: Little is known about the state of research in academic hospital medicine (HM) despite the substantial growth of this specialty.

METHODS: We used the Society of Hospital Medicine (SHM) membership database to identify research programs and their leadership. In addition, the members of the SHM Research Committee identified individuals who lead research programs in HM. A convenience sample of programs and individuals was thus created. A survey instrument containing questions regarding institutional information, research activities, training opportunities, and funding sources was pilot tested and refined for electronic dissemination. Data were summarized using descriptive statistics.

RESULTS: A total of 100 eligible programs and corresponding individuals were identified. Among these programs, 28 completed the survey in its entirety (response rate $28 \%$ ). Among the 1,586 faculty members represented in the 28 programs, 192 (12\%) were identified as engaging in or having obtained extramural funding for research, and 656 (41\%) were identified as engaging in quality improvement efforts. Most programs (61\%) indicated that they received $\$ 500,000$ or less in research funding, whereas $29 \%$ indicated that they received $>\$ 1$ million in funding. Major sources of grant support included the Agency for Healthcare Research and Quality, National Institutes of Health, and the Veterans Health Administration. Only five programs indicated that they currently have a research fellowship program in HM. These programs cited lack of funding as a major barrier to establishing fellowships. Almost half of respondents (48\%) indicated that their faculty published between 11-50 peerreviewed manuscripts each year.

CONCLUSION: This survey provides the first national summary of research activities in HM. Future waves of the survey can help determine whether the research footprint of the field is growing. Journal of Hospital Medicine 2018;14:207-211. (C) 2019 Society of Hospital Medicine

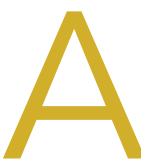

Imost all specialties in internal medicine have a sound scientific research base through which clinical practice is informed. ${ }^{1}$ For the field of Hospital Medicine (HM), this evidence has largely comprised research generated from fields outside of the specialty. The need to develop, invest, and grow investigators in hospital-based medicine remains unmet as $\mathrm{HM}$ and its footprint in hospital systems continue to grow. ${ }^{2,3}$

Despite this fact, little is known about the current state of research in HM. A 2014 survey of the members of the Society of Hospital Medicine (SHM) found that research output across the field of HM, as measured on the basis of peer-reviewed publications, was growing. ${ }^{4}$ Since then, however, the numbers of individuals engaged in research activities, their background and

*Corresponding Author: Vineet Chopra MD, MSc; E-mail: vineetc@umich.edu; Telephone: 734-936-4000; Twitter: @vineet_chopra

Received: September 13, 2018; Revised: November 6, 2018;

Accepted: December 2, 2018

(C) 2019 Society of Hospital Medicine DOI 10.12788/jhm.3136 training, publication output, or funding sources have not been quantified. Similarly, little is known about which institutions support the development of junior investigators (ie, HM research fellowships), how these programs are funded, and whether or not matriculants enter the field as investigators. These gaps must be measured, evaluated, and ideally addressed through strategic policy and funding initiatives to advance the state of science within HM.

Members of the SHM Research Committee developed, designed, and deployed a survey to improve the understanding of the state of research in HM. In this study, we aimed to establish the baseline of research in HM to enable the measurement of progress through periodic waves of data collection. Specifically, we sought to quantify and describe the characteristics of existing research programs, the sources and types of funding, the number and background of faculty, and the availability of resources for training researchers in HM.

\section{METHODS}

Study Setting and Participants

Given that no defined list, database, or external resource that 
identifies research programs and contacts in HM exists, we began by creating a strategy to identify and sample adult HM programs and their leaders engaged in research activity. We iteratively developed a two-step approach to maximize inclusivity. First, we partnered with SHM to identify programs and leaders actively engaging in research activities. SHM is the largest professional organization within $\mathrm{HM}$ and maintains an extensive membership database that includes the titles, e-mail addresses, and affiliations of hospitalists in the United States, including academic and nonacademic sites. This list was manually scanned, and the leaders of academic and research programs in adult HM were identified by examining their titles (eg, Division Chief, Research Lead, etc.) and academic affiliations. During this step, members of the committee noticed that certain key individuals were either missing, no longer occupying their role/title, or had been replaced by others. Therefore, we performed a second step and asked the members of the SHM Research Committee to identify academic and research leaders by using current personal contacts, publication history, and social networks. We asked members to identify individuals and programs that had received grant funding, were actively presenting research at SHM (or other major national venues), and/or were producing peer-reviewed publications related to HM. These programs were purposefully chosen (ie, over HM programs known for clinical activities) to create an enriched sample of those engaged in research in HM. The research committee performed the "second pass" to ensure that established investigators who may not be accurately captured within the SHM database were included to maximize yield for the survey. Finally, these two sources were merged to ensure the absence of duplicate contacts and the identification of a primary respondent for each affiliate. As a result, a convenience sample of 100 programs and corresponding individuals was compiled for the purposes of this survey.

\section{Survey Development}

A workgroup within the SHM Research Committee was tasked to create a survey that would achieve four distinct goals: (1) identify institutions currently engaging in hospital-based research; (2) define the characteristics, including sources of research funding, training opportunities, criteria for promotion, and grant support, of research programs within institutions; (3) understand the prevalence of research fellowship programs, including size, training curricula, and funding sources; and (4) evaluate the productivity and funding sources of $\mathrm{HM}$ investigators at each site.

Survey questions that target each of these domains were drafted by the workgroup. Questions were pretested with colleagues outside the workgroup focused on this project (ie, from the main research committee). The instrument was refined and edited to improve the readability and clarity of questions on the basis of the feedback obtained through the iterative process. The revised instrument was then programmed into an online survey administration tool (SurveyMonkey ${ }^{\circledR}$ ) to facilitate electronic dissemination. Finally, the members of the workgroup tested the online survey to ensure functionality. No identifiable information was collected from respondents, and no monetary incentive was offered for the completion of the survey. An invitation to participate in the survey was sent via e-mail to each of the program contacts identified.

\section{Statistical Analysis}

Descriptive statistics, including proportions, means, and percentages, were used to tabulate results. All analyses were conducted using Stata 13 MP/SE (StataCorp, College Station, Texas).

\section{Ethical and Regulatory Considerations}

The study was reviewed and deemed exempt from regulation by the University of Michigan Institutional Review Board (HUM000138628).

\section{RESULTS}

General Characteristics of Research Programs and Faculty

Out of 100 program contacts, 28 (representing 1,586 faculty members) responded and were included in the survey (program response rate $=28 \%$ ). When comparing programs that did respond with those that did not, a greater proportion of programs in university settings were noted among respondents (79\% vs $21 \%$ ). Respondents represented programs from all regions of the United States, with most representing university-based (79\%), university-affiliated (14\%) or Veterans Health Administration (VHA; 11\%) programs. Most respondents were in leadership roles, including division chiefs (32\%), research directors/leads (21\%), section chiefs (18\%), and related titles, such as program director. Respondents indicated that the total number of faculty members in their programs (including nonclinicians and advance practice providers) varied from eight to 152 (mean [SD] = 57 [36]) members, with physicians representing the majority of faculty members (Table 1).

Among the 1,586 faculty members within the 28 programs, respondents identified 192 faculty members (12\%) as currently receiving extra- or intramural support for research activities. Of these faculty, over half (58\%) received $<25 \%$ of effort from intra or extramural sources, and $28(15 \%)$ and 52 (27\%) faculty members received $25 \%-50 \%$ or $\geq 50 \%$ of support for their effort, respectively. The number of investigators who received funding across programs ranged from 0 to 28 faculty members. Compared with the 192 funded investigators, respondents indicated that a larger number of faculty in their programs ( $n=656$ or $41 \%$ ) were involved in local quality improvement (Ql) efforts. Of the 656 faculty members involved in $\mathrm{Ql}$ efforts, 241 individuals (37\%) were internally funded and received protected time/effort for their work.

\section{Key Attributes of Research Programs}

In the evaluation of the amount of total grant funding, respondents from 17 programs indicated that they received $\leq \$ 500,000$ in annual extra and intramural funding, and those from three programs stated that they received $\$ 500,000$ to $\$ 999,999$ in funding. Five respondents indicated that their programs currently received $\$ 1$ million to $\$ 5$ million in grant funding, and three reported $>\$ 5$ million in research support. The sources of research funding included several divisions within the National Institute of Health (NIH, 12 programs), Agency for 
TABLE 1. Characteristics of Survey Respondents and their Facilities ${ }^{a}$

\begin{tabular}{lc}
\hline Hospital Characteristics, $\mathbf{n}(\%)$ & Total ( $\mathbf{n}=\mathbf{2 8})$ \\
\hline Type of institution & $22(79 \%)$ \\
University teaching hospital & $4(14 \%)$ \\
University affiliated & $3(11 \%)$ \\
VA Hospital & $4(14 \%)$ \\
Other (eg, community or private) & \\
\hline Type of Hospital Medicine Group & $15(54 \%)$ \\
Division & $4(14 \%)$ \\
Program & $9(32 \%)$ \\
Section & \\
\hline Survey Respondent Title/Role & $9(32 \%)$ \\
Division chief & $6(21 \%)$ \\
Research director/lead & $5(18 \%)$ \\
Section chief & $8(29 \%)$ \\
Other (eg, director or chair) & \\
\hline Number of Faculty in Hospital Medicine Group & $57(8-152)$ \\
Total per hospital, mean (range) & 1,586 \\
Total (all provider types, n) & 1,293 \\
\hline Total number of physicians (n) & \\
\hline Columns may not add up to 100\% because respondents could select multiple categories.
\end{tabular}

Healthcare Research and Quality (AHRQ, four programs), foundations (four programs), and internal grants (six programs). Additionally, six programs indicated "other" sources of funding that included the VHA, Patient-Centered Outcomes Research Institute (PCORI), Centers for Medicare and Medicaid Services, Centers for Disease Control (CDC), and industry sources.

A range of grants, including career development awards (11 programs); small grants, such as R21 and R03s (eight programs); R-level grants, including VA merit awards (five programs); program series grants, such as $P$ and $U$ grants (five programs), and foundation grants (eight programs), were reported as types of awards. Respondents from 16 programs indicated that they provided internal pilot grants. Amounts for such grants ranged from $<\$ 50,000$ (14 programs) to $\$ 50,000-\$ 100,000$ (two programs).

\section{Research Fellowship Programs/Training Programs}

Only five of the 28 surveyed programs indicated that they currently had a research training or fellowship program for developing hospitalist investigators. The age of these programs varied from $<1$ year to 10 years. Three of the five programs stated that they had two fellows per year, and two stated they had spots for one trainee annually. All respondents indicated that fellows received training on study design, research methods, quantitative (eg, large database and secondary analyses) and qualitative data analysis. In addition, two programs included training in systematic review and meta-analyses, and three included focused courses on healthcare policy. Four of the five programs included training in $\mathrm{Q}$ t tools, such as LEAN and Six Sigma. Funding for four of the five fellowship programs
TABLE 2. Characteristics and Funding of Research and Fellowship Programs

\begin{tabular}{|c|c|}
\hline Funding of Research Programs & Total $(n=28)$ \\
\hline \multicolumn{2}{|l|}{ Sources of research funding } \\
\hline National Institute of Health & $12(43 \%)$ \\
\hline Agency for Healthcare Research and Quality & $4(14 \%)$ \\
\hline Foundations & $4(14 \%)$ \\
\hline Internal grants & $6(21 \%)$ \\
\hline Other (eg, VHA, PCORI, CMS, CDC, and industry) & $6(21 \%)$ \\
\hline \multicolumn{2}{|l|}{ Amount of extra and intramural funding } \\
\hline$<\$ 500,000$ & $17(61 \%)$ \\
\hline$\$ 500,000$ to $\$ 999,999$ & $3(11 \%)$ \\
\hline$\$ 1$ million - \$5 million & $5(18 \%)$ \\
\hline$>\$ 5$ million & $3(11 \%)$ \\
\hline \multicolumn{2}{|l|}{ Types of awards received } \\
\hline Career development & $11(39 \%)$ \\
\hline Small grants (eg, R21, R03) & $8(29 \%)$ \\
\hline R01 grants & $5(18 \%)$ \\
\hline Program series grants (eg, $\mathrm{P}$ and $\mathrm{U}$ ) & $5(18 \%)$ \\
\hline Foundation grants & $8(29 \%)$ \\
\hline Other (eg, PCORI and philanthropy) & $3(11 \%)$ \\
\hline \multicolumn{2}{|l|}{ Research Fellowship Programs/Training } \\
\hline Current research training or fellowship program at institution & $N=5$ \\
\hline \multicolumn{2}{|l|}{ Number of fellows per year } \\
\hline $0-1$ & $2(40 \%)$ \\
\hline 2 & $3(60 \%)$ \\
\hline \multicolumn{2}{|l|}{ Funding sources } \\
\hline Internal/intramural & $4(80 \%)$ \\
\hline Extramural & $2(40 \%)$ \\
\hline Other (eg, interdepartment funds, etc.) & $2(40 \%)$ \\
\hline $\begin{array}{l}\text { Abbreviations: CDC, Centers for Disease Control; CMS, Ce } \\
\text { and Medicaid Services; PCORI, Patient-Centered Outcome } \\
\text { Institute, VHA, Veteran's Health Administraction. }\end{array}$ & \\
\hline
\end{tabular}

came from internal sources (eg, department and CTSA). However, two programs added they received some support from extramural funding and philanthropy. Following training, respondents from programs indicated that the majority of their graduates (60\%) went on to hybrid research/Ql roles $(50 / 50$ research/clinical effort), whereas $40 \%$ obtained dedicated research investigator (80/20) positions (Table 2).

The 23 institutions without research training programs cited that the most important barrier for establishing such programs was lack of funding (12 programs) and the lack of a pipeline of hospitalists seeking such training (six programs). However, 15 programs indicated that opportunities for hospitalists to gain research training in the form of courses were available internally (eg, courses in the department or medical school) or externally (eg, School of Public Health). Seven programs indicated that they were planning to start a HM research fellowship within the next five years.

Research Faculty

Among the 28 respondents, 15 stated that they have faculty members who conduct research as their main professional ac- 


\section{TABLE 3. Characteristics of Research Faculty ${ }^{a}$}

\begin{tabular}{lc}
\hline Category & $\mathbf{n}$ \\
\hline Research Faculty by Institution & \\
\hline Institutions with faculty conducting research as their major activity (>50\% effort) & 15 \\
Number of faculty with research as major activity by hospital (range) & $1-10$ \\
At least one full time professor conducting research & $4(27 \%)$ \\
At least one associate professor conducting research & $8(53 \%)$ \\
At least one assistant professor conducting research & $12(80 \%)$ \\
At least one clinical instructor conducting research & $4(27 \%)$ \\
\hline Main focus of faculty research (>50\% effort) & $11(73 \%)$ \\
Health services & $1(7 \%)$ \\
Basic sciences & $4(27 \%)$ \\
Clinical trials & $1(7 \%)$ \\
Other (ie, informatics) &
\end{tabular}

Domains studied by research faculty

Quality and process improvement $\quad 19(68 \%)$

Patient safety $\quad 17(61 \%)$

$\begin{array}{ll}\text { Disease-specific } & 15(54 \%)\end{array}$

Other (ie, bioethics and disparities in care) $\quad 6(21 \%)$

Approximate number of peer-reviewed publications per year

$\begin{array}{ll}0-10 & 10(40 \%) \\ 11-50 & 12(48 \%) \\ 50-99 & 3(12 \%)\end{array}$

Research abstracts

$0-10$

$13(52 \%)$

$11-50$

$12(48 \%)$

Faculty Support for Research Effort

\begin{tabular}{lc}
\hline Number of faculty involved in research & 192 \\
\hline$\%$ extra or intramural support for research activities & \\
$<25 \%$ effort support & $112(58 \%)$ \\
$25 \%-50 \%$ effort support & $28(15 \%)$ \\
$>50 \%$ effort & $52(27 \%)$ \\
\hline Number of faculty involved in quality improvement & 656 \\
With protected effort & $241(37 \%)$ \\
Without protected effort & $415(63 \%)$ \\
\hline Number of research faculty involved in teaching & 1,168 \\
With protected effort & $256(22 \%)$ \\
Without protected effort & $912(78 \%)$
\end{tabular}

${ }^{a}$ A total of 28 programs representing 1,586 faculty members were included. Of these, 192 faculty members were identified as receiving extra or intramural funding.

tivity (ie, $>50 \%$ effort). The number of faculty members in each program in such roles varied from one to 10. Respondents indicated that faculty members in this category were most often midcareer assistant or associate professors with few full professors. All programs indicated that scholarship in the form of peer-reviewed publications was required for the promotion of faculty. Faculty members who performed research as their main activity had all received formal fellowship training and consequently had dual degrees (MD with MPH or MD, with $\mathrm{MSc}$ being the two most common combinations). With respect to clinical activities, most respondents indicated that research faculty spent $10 \%$ to $49 \%$ of their effort on clinical work. However, five respondents indicated that research faculty had $<10 \%$ effort on clinical duties (Table 3).

Eleven respondents (39\%) identified the main focus of faculty as health service research, where four (14\%) identified their main focus as clinical trials. Regardless of funding status, all respondents stated that their faculty were interested in studying quality and process improvement efforts (eg, transitions or readmissions, $n=19$ ), patient safety initiatives (eg, hospital-acquired complications, $n=17$ ), and disease-specific areas (eg, thrombosis, $n=15$ ).

In terms of research output, 12 respondents stated that their research/QI faculty collectively published 11-50 peer-reviewed papers during the academic year, and 10 programs indicated that their faculty published 0-10 papers per year. Only three programs reported that their faculty collectively published 50-99 peer-reviewed papers per year. With respect to abstract presentations at national conferences, 13 programs indicated that they presented 0-10 abstracts, and 12 indicated that they presented 11-50.

\section{DISCUSSION}

In this first survey quantifying research activities in HM, respondents from 28 programs shared important insights into research activities at their institutions. Although our sample size was small, substantial variation in the size, composition, and structure of research programs in $\mathrm{HM}$ among respondents was observed. For example, few respondents indicated the availability of training programs for research in $\mathrm{HM}$ at their institutions. Similarly, among faculty who focused mainly on research, variation in funding streams and effort protection was observed. A preponderance of midcareer faculty with a range of funding sources, including $\mathrm{NIH}, \mathrm{AHRQ}, \mathrm{VHA}, \mathrm{CMS}$, and $\mathrm{CDC}$ was reported. Collectively, these data not only provide a unique glimpse into the state of research in $\mathrm{HM}$ but also help establish a baseline of the status of the field at large.

Some findings of our study are intuitive given our sampling strategy and the types of programs that responded. For example, the fact that most respondents for research programs represented university-based or affiliated institutions is expected given the tripartite academic mission. However, even within our sample of highly motivated programs, some findings are surprising and merit further exploration. For example, the observation that some respondents identified HM investigators within their program with $<25 \%$ in intra- or extramural funding was unexpected. On the other extreme, we were surprised to find that three programs reported $>\$ 5$ million in research funding. Understanding whether specific factors, such as the availability of experienced mentors within and outside departments or assistance from support staff (eg, statisticians and project managers), are associated with success and funding within these programs are important questions to answer. By focusing on these issues, we will be well poised as a field to understand what works, what does not work, and why.

Likewise, the finding that few programs within our sample 
offer formal training in the form of fellowships to research investigators represents an improvement opportunity. A pipeline for growing investigators is critical for the specialty that is HM. Notably, this call is not new; rather, previous investigators have highlighted the importance of developing academically oriented hospitalists for the future of the field..$^{5}$ The implementation of faculty scholarship development programs has improved the scholarly output, mentoring activities, and succession planning of academics within HM. ${ }^{6,7}$ Conversely, lack of adequate mentorship and support for academic activities remains a challenge and as a factor associated with the failure to produce academic work. ${ }^{8}$ Without a cadre of investigators asking critical questions related to care delivery, the legitimacy of our field may be threatened.

While extrapolating to the field is difficult given the small number of our respondents, highlighting the progress that has been made is important. For example, while misalignment between funding and clinical and research mission persists, our survey found that several programs have been successful in securing extramural funding for their investigators. Additionally, internal funding for Ol work appears to be increasing, with hospitalists receiving dedicated effort for much of this work. Innovation in how best to support and develop these types of efforts have also emerged. For example, the University of Michigan Specialist Hospitalist Allied Research Program offers dedicated effort and funding for hospitalists tackling projects germane to HM (eg, ordering of blood cultures for febrile inpatients) that overlap with subspecialists (eg, infectious diseases). ${ }^{9}$ Thus, hospitalists are linked with other specialties in the development of research agendas and academic products. Similarly, the launch of the HOMERUN network, a coalition of investigators who bridge health systems to study problems central to HM, has helped usher in a new era of research opportunities in the specialty. ${ }^{10}$ Fundamentally, the culture of HM has begun to place an emphasis on academic and scholarly productivity in addition to clinical prowess. ${ }^{11-13}$ Increased support and funding for training programs geared toward innovation and research in $\mathrm{HM}$ is needed to continue this mission. The Society for General Internal Medicine, American College of Physicians, and SHM have important roles to play as the largest professional organizations for generalists in this respect. Support for research, $\mathrm{Ql}$, and investigators in HM remains an urgent and largely unmet need.

Our study has limitations. First, our response rate was low at $28 \%$ but is consistent with the response rates of other surveys of physician groups. ${ }^{14}$ Caution in making inferences to the field at large is necessary given the potential for selection and nonresponse bias. However, we expect that respondents are likely biased toward programs actively conducting research and engaged in Ql, thus better reflecting the state of these activities in HM. Second, given that we did not ask for any identifying information, we have no way of establishing the accuracy of the data provided by respondents. However, we have no reason to believe that responses would be altered in a systematic fashion. Future studies that link our findings to publicly avail- able data (eg, databases of active grants and funding) might be useful. Third, while our survey instrument was created and internally validated by hospitalist researchers, its lack of external validation could limit findings. Finally, our results vary on the basis of how respondents answered questions related to effort and time allocation given that these measures differ across programs.

In summary, the findings from this study highlight substantial variations in the number, training, and funding of research faculty across HM programs. Understanding the factors behind the success of some programs and the failures of others appears important in informing and growing the research in the field. Future studies that aim to expand survey participation, raise the awareness of the state of research in HM, and identify barriers and facilitators to academic success in HM are needed.

Disclosures: Dr. Chopra discloses grant funding from the Agency for Healthcare Research and Quality (AHRQ), VA Health Services and Research Department, and Centers for Disease Control. Dr. Jones discloses grant funding from AHRQ. All other authors disclose no conflicts of interest.

\section{References}

1. International Working Party to Promote and Revitalise Academic Medicine. Academic medicine: the evidence base. BMJ. 2004;329(7469):789-792. doi: 10.1136/bmj.329.7469.789

2. Flanders SA, Saint S, McMahon LF, Howell JD. Where should hospitalists sit within the academic medical center? J Gen Intern Med. 2008;23(8):12691272. doi: 10.1007/s11606-008-0682-1.

3. Flanders SA, Centor B, Weber V, McGinn T, Desalvo K, Auerbach A. Challenges and opportunities in academic hospital medicine: report from the academic hospital medicine summit. J Gen Intern Med. 2009;24(5):636-641. doi: 10.1007/s11606-009-0944-6

4. Dang Do AN, Munchhof AM, Terry C, Emmett T, Kara A. Research and publication trends in hospital medicine. J Hosp Med. 2014;9(3):148-154. doi: 10.1002/jhm.2148.

5. Harrison R, Hunter AJ, Sharpe B, Auerbach AD. Survey of US academic hospitalist leaders about mentorship and academic activities in hospitalist groups. J Hosp Med. 2011;6(1):5-9. doi: 10.1002/jhm.836.

6. Sehgal NL, Sharpe BA, Auerbach AA, Wachter RM. Investing in the future: building an academic hospitalist faculty development program. J Hosp Med. 2011;6(3):161-166. doi: 10.1002/jhm.845.

7. Nagarur A, O'Neill RM, Lawton D, Greenwald JL. Supporting faculty development in hospital medicine: design and implementation of a personalized structured mentoring program. J Hosp Med. 2018;13(2):96-99. doi: 10.12788/ jhm.2854.

8. Reid MB, Misky GJ, Harrison RA, Sharpe B, Auerbach A, Glasheen JJ. Mentorship, productivity, and promotion among academic hospitalists. J Gen Intern Med. 2012;27(1):23-27. doi: 10.1007/s11606-011-1892-5.

9. Flanders SA, Kaufman SR, Nallamothu BK, Saint S. The University of Michigan Specialist-Hospitalist Allied Research Program: jumpstarting hospital medicine research. J Hosp Med. 2008;3(4):308-313. doi: 10.1002/jhm.342.

10. Auerbach AD, Patel MS, Metlay JP, et al. The Hospital Medicine Reengineering Network (HOMERuN): a learning organization focused on improving hospital care. Acad Med. 2014;89(3):415-420. doi: 10.1097/ ACM.0000000000000139.

11. Souba WW. Academic medicine's core values: what do they mean? J Surg Res. 2003;115(2):171-173. doi: 10.1016/j.jss.2003.09.016.

12. Bonsall J, Chopra V. Building an academic pipeline: a combined society of hospital medicine committee initiative. J Hosp Med. 2016;11(10):735-736. doi: 10.1002/jhm.2627.

13. Sweigart JR, Tad YD, Kneeland P, Williams MV, Glasheen JJ. Hospital medicine resident training tracks: developing the hospital medicine pipeline. J Hosp Med. 2017;12(3):173-176. doi: 10.12788/jhm.2703.

14. Cunningham $C T$, Quan $H$, Hemmelgarn B, et al. Exploring physician specialist response rates to web-based surveys. BMC Med Res Methodol. 2015:15(1):32. doi: 10.1186/s12874-015-0016-z. 